\title{
COMMUNITY HEALTH WORKERS IN GAZANKULU
}

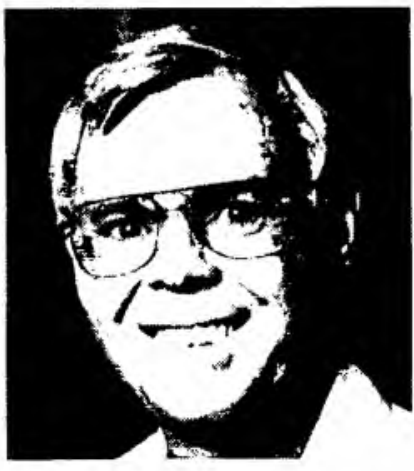

J. C. N. Mentz

\section{INTRODUCTION}

The aim of this paper is to give a brief description of the utilization of community health workers (CHWs) in Gazankulu. The general policy framework in which these health workers function is described briefly, and the way in which these workers function evaluated. This paper is intended as a modest contribution to evaluation research in the field of community health.

\section{THE GAZANKULU HEALTH SERVICE}

Geographical location of Gazankulu Gazankulu is one of the self-governing "national states" within the Republic of South Africa. Its territory is divided into four geographically separate blocks: the Mhala area in the south-east between Acornhoek and Bushbuckridge; Ritavi 1 and 2 situated east of Tzaneen; and Giyani in the north-east. Giyani consists of three magisterial districts: Malamulele in the east, Giyani in the centre and Elim in the west.

At present the territory of Gazankulu covers an estimated 675000 hectares or $6750 \mathrm{~km}^{2}$ - an area which will be increased slightly after consolidation. Gazankulu shares borders with Venda to the north, Lebowa (both Ritavi 1 and 2 and Mhala) and of course the RSA at various points. This division of its area into four blocks has a negative influence on the administration of the territory and also on its health service delivery system. The de facto population of Gazankulu was estimated in 1980 at 480000 . The results of the 1985 census were not available at the time of writing.

-The research upon which this research is based, was undertaken with the aid of a research grant from the University of South Africa. I also acknowledge constructive criticism from my colleagues in the Department of Development Administration and Politics. It should, however, be emphasized that the conclusions drawn and the opinions expressed are my own, and that none of the abovementioned persons or institutions are in any way responsible for any of the shortcomings from which this paper may suffer.

DEPARTMENT OF HEALTH AND WELFARE

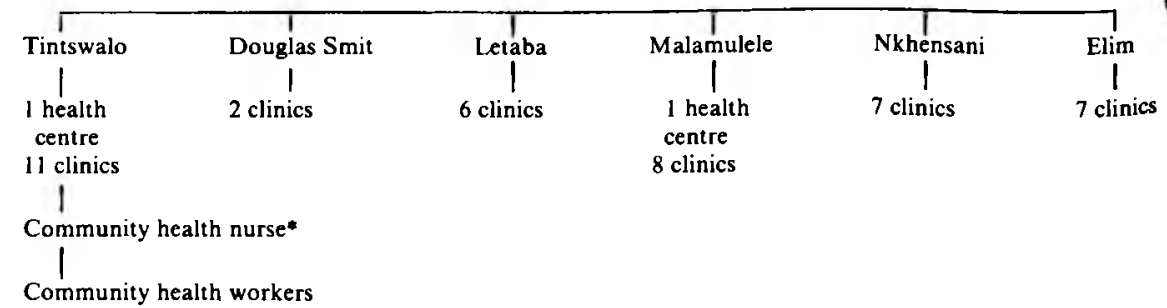

The annual rainfall is low $(500-700$ $\mathrm{mm} /$ year) and seasonal. An estimated $80 \%$ of the rainfall occurs between the months of October and April. The topography of the territory varies from mopani shrub lowveld in the eastern parts to hilly broken terrain in the Elim district.

From data compiled by the Rand Afrikaans University (1983) it appears that the age profile of the population of Gazankulu is relatively young. Approximately $53 \%$ of the inhabitants are 15 years of age and younger - a fairly common tresd in the Third World.

Health service structure in Gazankulu The head office of the Gazankulu Department of Health and Welfare is in Giyani and is responsible for the organization and control of all health services in the national state. The territory is divided into a number of health wards. The hospital forms the nucleus of the health service in the health ward and is responsible for all levels of health care including community health. In each health ward a number of clinics are established to provide a more even distribution of health services to the local population. In the more remote areas visiting points by mobile units are also provided. The health services offered at such visiting points include mother and child care, immunizations and other aspects of community health, such as education on the importance of proper sanitation, the necessity of pure water for domestic use, and nutrition.
The organization of the health services provided to the inhabitants of Gazankulu can be shown graphically as follows:

\section{OBJECTIVE OF THE STUDY OF COMMUNITY HEALTH WORKERS (CHWs)}

The employment of CHWs may be regarded as a very important component of primary health care. The question whether this view is generally accepted borne out by the practice as observed ir Gazankulu.

Primary health care must be seen within the context of the definition of the concept as defined in the declaration issued by the World Health Organization (WHO, 1978):

"Primary health care is essential health care based on practical, scientifically sound and socially acceptable methods and technology made universally accessible to individuals and families in the community through their full participation and at a cost that the community can afford to maintain at every stage of their development in the spirit of self-reliance and self-determination. It forms an integral part both of the country's health system, of which it is the central function and focus, and of the overall social and economic development of the community. It is the

*A community health nurse is attached to each hospital in the various health wards. She is responsible for community health in the area and is assisted in the execution of her duties by health inspectors. One of the responsibilities of the community health nurse is the supervision of the community health workers ( $\mathrm{CHWs}$ ) to which we shall return later in this paper. 
first level of contact of the individual, the family and the community with the national health system bringing health care as close as possible to where people live and work, and constitutes the first element of a continuing health care process" (WHO 1978:3-4). From the above it is clear that primary health care forms an integral part of any programme of community development which is aimed at improving the quality of life of the community in general. It may also help significantly to eradicate indigence and to break the vicious circle of poverty in which Third World nations are caught up.

Health conditions in Gazankulu bear close resemblance to that of other Third World countries. From interviews with people responsible for the introduction of CHWs to the Gazankulu health service delivery system at that time (ca 1980) it is clear that they were heavily influenced by the thinking of the WHO as is reflected in the above definition. Introducing $\mathrm{CHWs}$ was an attempt to make health care accessible to local communities in

rankulu and at a cost that they could rord.

The employment of voluntary workers in health service delivery systems is generally regarded as one of the most important factors in the successful implementation of a programme of primary health care (Werner, 1977). In the "Blueprint of Objectives 1978 - 83" issued by the Department of Health and Welfare in Gazankulu provision was made for the creation of a new category of health worker, the community health worker. This was done in an attempt to bring health care within easy reach of every inhabitant of the territory. This intent was re-emphasized by the then Minister of Health (Rev. Kubayi), who said in her budget speech in 1984 "our policy still aims at improving and expanding all health services with an increasing accent on community health, and ensuring that the population of Gazankulu can afford and access to curative, preventive and prumotive services at a cost that everybody can afford, and within a reasonable distance of one's residence."

In this paper it is maintained that the community health worker has a positive influence on the health of a community. The aim with this research was to establish whether the above statement is valid or not.

After a study of the relevant literature, a number of visits were made to Gazankulu. Subsequently a questionnaire was drafted, in which use was made, inter alia, of the syllabus used in the training of community health workers as well as of the duty sheet issued to each community health worker when she commenced working in the village.' In the interviews with the respondents attention was given to degree to which particular health messages as well as other aspects of community health have taken root or have been accepted by the community.

\section{Research methods}

\section{Choice of communities}

It was decided to restrict the survey to the
Giyani area (in other words to the magisterial districts of Malamulele, Giyani and Elim) due to the long distances between the four blocks comprising Gazankulu. The inclusion of the Ritavi 1 and 2 blocks as well as the Mhala area would have required a budget far greater than that available for this research.

More important, however, was that some work has been done on the CHWs in the Mhala area (Hammond \& Buch, 1984) and also on the care groups ${ }^{2}$ in the Elim district (Karlsson, 1983) while no such work has been done on the CHWs in the Giyani area.

The present and former Directors of the Elim Care Group Project were interviewed to gain a better understanding of community health in Gazankulu. In addition interviews were held with senior officials of the Department of Health and Welfare in Giyani.

After reconnoitring the field in this manner, four villages were selected for the survey: one in the Malamulele district; one in the Giyani district; and two in the Elim district. These four villages were selected on the following grounds:

a. Matiyani in the Malamulele district was selected because it is fairly remote and no $\mathrm{CHW}$ is working there. The village is situated approximately $60 \mathrm{~km}$ from the Malamulele Hospital and $15 \mathrm{~km}$ from the nearest clinic at Mhinga.

b. Hlomela in the Giyani district is $56 \mathrm{~km}$ directly east of the Nkhensani Hospital, by dirt road often unpassable in the rainy season. It is also $45 \mathrm{~km}$ from the nearest clinic. A fairly active $\mathrm{CHW}$ is working in the village. Hlomela is also a visiting point for the mobile unit operating from Nkhensani Hospital. A daily bus service operates between Giyani and Hlomela. ${ }^{3,4}$ No other form of communication exists between the hospital and the village (i.e. telephone or radio)

c. Wayeni in the Elim district was chosen because a fairly active $\mathrm{CHW}$ was working in the yillage. This little village is also fairly remote $-30 \mathrm{~km}$ from Elim Hospital - a mountain range separates the hospital from the village and the nearest clinic at Gavaza is 5 or $6 \mathrm{~km}$ distant. No other means of direct communication exists between the hospital and the village.

d. Riverplaats is also in the Elim district and was chosen because of its remoteness - situated in a secluded valley approximately $30 \mathrm{~km}$ from Elim Hospital. Apparently the $\mathrm{CHW}$ is not very active. This village is also a visiting point of the mobile clinic operating from Elim Hospital

To summarize - a CHW was employed in three of the four villages under the supervision of the community health nurse from the nearest hospital. Matiyani could therefore be regarded as a control group in testing some of the knowledge of the local village communities of certain aspects of community health.

Choice of the sample

Hlomela and Wayeni are essentially resettlement villages. After consolidation Matiyani and Hlomela were surveyed by officials of the Department of Agriculture, and a number of people were resettled mostly from Venda - in the two areas. A map of Matiyani was obtained from the local magistrate, showing the numbered stands. By using a random sample numbering table, 33 out of 315 households 5,6 were selected, giving a sample of $10,5 \%$. It was relatively easy to trace the stand numbers which could be cross-checked against the stand cards issued to each household. In cases where a stand was vacant its neighbour on the right-hand side was selected.

In Hlomela it would appear that no numbers have been allocated to the stands. A rough map of the village was therefore drawn on which each household was numbered. The random sample numbering table was also used in this case giving a sample of 30 out of 145 households, thus a sample of $21 \%$.

In the case of Riverplaats and Wayeni a different method was used to draw a sample. One reason was that Riverplaats was not surveyed and that although Wayeni is also a resettlement village, it was difficult to distinguish separate stands.

The method used to obtain a sample in Riverplaats was based on a method first employed by Kok \& Kwamanga (1982) and subsequently used in a survey in the Elim district by Ijsselmuiden. The following is a summary of Ijsselmuiden's version of the method.

Basically this random sample technique is based on two assumptions:

a. School attendance is high. This observation was confirmed by comparing school attendance figures from Gazankulu's Department of Education and Culture with population estimates. This produced an estimate of $208 \%$ of children of school-going age (6 years) actually attending school.

According to Ijsselmuiden this unnaturally high percentage can be explained by the fact that on the one hand there is a tendency in the Elim district to enter children into school at an increasingly young age, though there are still many older children entering school at the age of 10-12. This conclusion was confirmed by subjective observation that during school term very few children of school-going age are seen in the villages (Ijsselmuiden, n.d. 3).

b. School attendance of Sub-Standard A children is the highest of all schoolgoing children (from Primary to Secondary School), and it is likely that these children will be randomly, and thus proportionately, distributed throughout the village (Ijsselmuiden)

Based on these assumptions the following procedure was adopted. A cumulative list was compiled of all the children attending Sub-Standard $A$ at Wayeni and Riverplaats.

Subsequently the principals of the primary schools of Riverplaats and Wayeni were visited and permission obtained from them to draw a sample from 
the Sub-Standard A classes. Using these class lists the names of five children were selected, giving five clusters of five children each in the two villages. Each child was then asked to lead the researcher to his household. This house was excluded from the survey because it had "a Sub A school child"(Ijsselmuiden). Five households in close proximity to this household were then selected for the survey and the head woman in each household was interviewed. In this manner 21 out of 361 households $(5,8 \%)$ were selected in Riverplaats and 29 out of $225(12,9 \%)$ households in Wayeni.

The following observations on the application of this sampling technique can be made:

a. The exclusion of a household with a child in Sub-Standard A has some validity but does not apply in all cases.

b. An even spread of households throughout the village was obtained.

c. Selecting a house in close proximity to the first one did present problems. In Riverplaats the village is situated in a narrow valley on two ridges and obtaining a household close to the firs one was quite difficult - sometimes stretching to a distance of 200 metres or more. In the case of Wayeni although there were one or two "straight" streets, households were unevenly spaced and it was quite difficult to obtain a cluster of five households in close proximity to one another.

A young man who had recently completed his matriculation examination was employed as a research assistant. All interviews were conducted with his assistance. Permission to conduct interviews was usually obtained from the senior wife; only in one instance was such permission refused. A week was spent in each village and interviews were also conducted with the local headmen, shopkeepers and the CHWs concerned.

\section{COMMUNITY HEALTH WORKERS \\ Background}

The Gazankulu "Blueprint of Objectives

$1978-83$ ", to which reference has already been made, provided for the "creation of a new category of health worker, the Community Health Worker: to be chosen by a community, trained by the health services (but needed a minimum qualification of Std. 6) and paid by the health services. The Community Health Worker would perform mainly preventive tasks in his/her village."

Each community health nurse was issued with instructions concerning $\mathrm{CHW}_{\mathrm{s}}$ in which it was stipulated that a CHW should be appointed at a public meeting to be held in the village. What happened in practice, however, was that the local headman often appointed a relative (Karlsson 1983:728; Hammond \& Buch 1984:6). Hammond \& Buch (1984:6) even reported a case where the popularly-elected candidate was still waiting to be sent for training when a relative of the local headman arrived back in the village as the trained $\mathrm{CHW}$.

The instructions also required that the CHW should be a mature person, older than 27 and have at least Std VI. To this Karlsson (1983:729) added that she should be a member of the local community and have a house which she could use as a base for the execution of her duties.

CHWs were trained partly at the Nkhensani Hospital (6-10 weeks) and partly at the Mphambo Health Centre.

Karlsson ${ }^{6}$ (1983:729), however, mentions a training period of 6-8 months of which 4-6 weeks was spent at the hospital. It is not clear what the actual length of training was

from information obtained during the research it would appear as if the firstmentioned period is the correct one.

Only three groups, each consisting of 12 trainees, were trained. According to Karlsson (1983:728) one of the CHWs never started to work, two left the service because their husbands moved out of the community where they were placed, 8 elected to work in a clinic and not in a community and in four cases the local communities were not satisfied with the behaviour of the CHWs in their households and also dissatisfied with the general performance of their duties

The training was stopped because a suitable person could not be found to conduct it and also because the Gazankulu Department of Health and Welfare is currently rethinking the concept of CHWs and their role in health service delivery. It could not be established exactly why the Department stopped the programme and answers to questions on this were rather vague.

In their evaluation of the role and functions of CHWs Hammond \& Buch (1984:8) make the point that the person training these people should make use of an "appropriate adult educational approach". To this the authors added that these people should also have experience in community work (the general principles of community development) primary health care and adult education. It is however, unlikely that persons meeting these requirements will easily be found in an area where there is already a shortage of professıonally trained people. However, my own survey should be seen as an attempt to evaluate the system and propose suitable alternatives.

\section{Distribution of community health workers} CHWs are distributed over the three magisterial districts in Giyani as follows:

a. Six in the Elim health ward*: 5 with Std 6-education and one with a Junior Certificate. All were married and only one is younger than 30 years of age, three older than 40 while the remainder are approximately 30 years old.

b. Six in the Malamulele health ward*: no information with regard to level of education, age or marital status could be obtained.

c. Five in the Nkensani health ward*: in this case also no information with regard to level of education, age and

* The distribution per health ward is given because the CHWs are distributed according to hospital wards and are supervised by the community health nurse attached to each hospital. marital status could be obtained

Hammond \& Buch (1984:6) on the other hand found that in the Mhala area the $\mathrm{CHWs}$ were often young women, frequently in their teens. At least in the Elim Health Ward this was not the case as well as was the case in one or two instances in the Malamulele and Nkhensani Health Wards. As a rule CHWs were placed in more remote rural areas with no other health facility nearby.

\section{Training syllabus}

The syllabus for the training of CHWs is prescribed by the SA Nursing Council. According to Karlsson (1983:729) there are two reasons for this, firstly that this formal recognition accords CHWs a legal status as part of the nursing profession which is important in the execution of their duties, and secondly because registration creates a professional career structure ensuring a measure of professional discipline. We shall return to this aspect later on in this paper.

The syllabus includes the following ethics, basic nursing (including anatomy), first aid; nutrition, hygiene (personal and environmental); prenatal and antenatal care (which includes a compulsory period of service in a labour ward); community development; health education and communication; and chronic diseases.

The practical work during training includes the following: gardening; the conserving of energy through the use of wonder-boxes and mud-stoves; drawing a plan of a village; community diagnosis, home visits, care groups, drafting reports and home economics.

The guidelines for the presentation of the syllabus described the course's aim as follows: to train the $\mathrm{CHW}$ "to cope with ELEMENTARY primary health care in her own community" (Syllabus, 1981). For this reason the training should be "community based and orientated" and focussed on "promotion of health and prevention of diseases".

To achieve this aim $\mathrm{CHWs}$ were encouraged to give priority to the following aspects (Syllabus, 1981):

a. Mother and child care.

b. Prevention of infectious diseases.

c. Continuous surveillance of the general health situation in the community and the identification of urgent health problems.

d. Follow-up of cases at risk, such as TB, malnutrition, psychiatric cases, and chronically ill persons.

e. First aid.

f. Homecraft, cooking, gardening and mudstoves.

In a job description issued to each $\mathrm{CHW}$ the following aspects were added to the above list. A CHW must set an example in the community by having:

- a toilet

- a refuse pit

- a vegetable garden

- separate facecloths for each member of her family.

- her children regularly immunized and also attending the underfives clinic. 
She should also keep her household and its surroundings clean, take care with her personal appearance and look after her uniform.

Evaluation of the syllabus

In a letter to the former Secretary of Health and Welfare, Dr Erica Sutter (then Director of the Elim Care Group Project), commented on the three training course of CHWs.

Her observations can be divided in two categories: the evaluation of theoretical training at the Nkhensani Hospital; and the practical work at the Mphambo Health Centre.

The syllabus used at Nkhensani for the first group was prepared by the head office staff of the Department of Health and Welfare with very little input from the hospital staff. At that stage an advanced course for the training of nursing assistants was being offered at the Nkhensani Hospital and the training of a category of

with workers at such a relatively low I of expertise was foreign to them. Consequently the hospital staff was uncertain as to what exactly was expected of them.

The whole issue was subsequently discussed with the hospital tutors and the syllabus for the training of the next group was amended accordingly. According to Sutter (1982) this new syllabus was better adapted to the situation prevailing in Gazankulu at that time and gave the students a better insight into the functioning of the hospital as well as training them in basic nursing practice.

The third group was less fortunate as their syllabus got lost (Sutter, 1982). It is not clear why the previous syllabus was not used. The students were therefore only trained in sophisticated hospital care.

The practical training at the Mphambo Health Centre was handled by staff from head office of the Department of Health

Welfare. Before they started with the tical training the syllabus was

discussed intensively with those members allocated to the training programme. The general feeling among the staff was that the lectures were quite adequate (Sutter, 1982). However, there was one problem, namely that the head office staff were not able to spend sufficient time with the group (it should be borne in mind that Mphambo is $30 \mathrm{~km}$ from Giyani). As a result the students were left to their own devices in the afternoons.

Another problem was that the person made responsible for practical training had insufficient experience especially with regard to adult education and the organization of a training course. The staff attached to the Health Centre were either unwilling or incapable to participate in the training sessions, especially where this involved accompanying students on home visits. The fact that there was such a heavy reliance on local staff led to the employment of training personnel with insufficient experience and consequently the lowering of the general standard of training. Tutors were also incapable of teaching students the skills and principles of community development because they themselves had no experience of it.

One of the most important technical problems was that the transport facilities at the health centre were inadequate to meet the requirements of the students. Consequently no visits could be made to households at any distance from the Health Centre. Home visits were therefore restricted to communities close to the Health Centre. These households complained that too many visits were paid to them while the more outlying communites complained of being neglected.

One very important problem was that the Director of the Elim Care Group Project lived at the Elim Hospital -80 $\mathrm{km}$ by a poor dirt road from the Health Centre. It became impossible for her to give adequate supervision and guidance to the programme. During this time the Secretary of Health and Welfare left Giyani to take up a position elsewhere and this was a further negative influence on the development of the programme. Frequent turnover of staff at head office also had an adverse effect on the programme's development.

\section{Functioning of the community health workers}

It is expected that $\mathrm{CHWs}$ will undertake regular surveys of the community in which they live, by means of regular home visits. The duty sheet, however, failed to stipulate how many visits should be carried out in the course of a normal working day. During a home visit the $\mathrm{CHW}$ is expected to be alert to any health problem needing urgent medical care, such as pregnancies; the health status of children under five years of age; whether there is a toilet and a refuse pit; the general condition of the household (environmental health); the presence of chronically ill people; and whether TB and psychiatric patients are taking their medication regularly.

Where necessary the $\mathrm{CHW}$ should give advice on the use of the oral rehydration solution for the treatment of diarrhoea, elementary first-aid, hygiene, and mother and child care.

Gazankulu's clinics set aside one day per week for child care: this is generally known as the child health day. It is expected that on this day CHWs will assist the nurse in charge of the underfives clinic, usually with weighing and immunizations.

The CHWs should assist families to establish a vegetable garden, build mudstoves, and to use wonder-boxes. It is also expected that the $\mathrm{CHW}$ will work hand-inhand with the local care group, and if such a group does not exist in the village to assist the women of the village to establish one. Finally it is also expected that the CHW will work closely with local leaders, such as the headman and church leaders.

On appointment every $\mathrm{CHW}$ is given a duty sheet containing general instructions on her duties. In this document she is admonished "to be friendly to every one and give the best care you are able to give, regardless of the patient's status or beliefs". She is cautioned against the use of any nursing practice for which she has not been trained, and told that anything beyond her capability should be referred to the nearest clinic or hospital. She is also reminded of the importance of professional confidentiality. Most important of all, she is warned to listen to the people before advising or teaching any person or group.

The CHW have prescribed working hours. It is expected that the $\mathrm{CHW}$ will report every morning to the tribal office, or, where there is no tribal office, as is the case in Hlomela and Wayeni, to report to the local headman when she starts working. Likewise she has to report to the tribal office or headman when going home in the evening. This is to ensure that the CHW may be easily traced when needed as when the community health nurse or one of the local doctors is visiting the village.

Each CHW is issued with a kit containing the following: first aid, a Salter scale, Road-to-health charts; temperature strips; aspirin (both junior and adult); malaria tablets and cotton wool and swabs. She is also issued with an ordering book for her kit and stationery and she is expected to keep files for monthly reports daily reports, family care as well as a personal file.

\section{Evaluation of the training of community} health workers

A number of provisional remarks on the training of community health workers may now be made though this aspect will be dealt with more fully further on.

First of all, the syllabus for the training of CHWs is by any standards a demanding one, bearing in mind that $\mathrm{CHWs}$ are at par with the lowest grade of nurses, viz. the nursing assistant. It is difficult to see how this syllabus can be covered effectively in the short space of time allowed to it, namely 6-10 weeks. The question could also be asked whether the minimum level of schooling required, Std 6, equips them sufficiently to master this course.

A second issue relates to the time actually spent doing practical work. Is there a sufficient balance between the theoretical work taught at Nkhensani Hospital and the practical work done at the Mphambo Health Centre? Or was the theory given preference to practical work?

A third issue relates to the duties expected of the CHW when she returns to her village after completion of the training One could also formulate this as a question: does the training of the $\mathrm{CHW}$ equip her adequately to handle the responsibilities attached to this job? Of the CHWs met during the field work few commanded sufficient English to cope with elementary questions. This should be seen against the fact that the medium of instruction used during training was English. This language is also used in duty sheets and other written instructions. Therefore their relatively low level of education reflects seriously on their ability to understand instructions given to them and to handle this job. 
THE COMMUNITY HEALTH NURSE

The community health nurse is responsible for the general supervision of the work of all $\mathrm{CHW}$ s working in a specific health ward. She has to prepare the local community before the $\mathrm{CHW}$ returns from training. The community health nurse should then introduce the $\mathrm{CHW}$ to the local headman, other members of the tribal authority as well as to the community and explain the function and duties of the CHW to them and what they may expect of her.

Each community health nurse is issued with a duty sheet detailing her responsibilities in respect of the $\mathrm{CHWs}$. It is recommended that she should also spend at least a week full-time in the field with each $\mathrm{CHW}$. She must also assist the $\mathrm{CHW}$ in the planning of her daily or weekly routine and in determining local health priorities. Discussing this aspect of her work, one of the community health nurses said that although she initially tried to visit all the CHWs in her ward at least once a week, pressure of work and the long distances involved forced her to reduce this to a single monthly visit (Karlsson, 1983:728). Such a visit normally lasted from half-an-hour to an hour. In another health ward the community health nurse spent from two to three hours on a visit to the $\mathrm{CHWs}$ under her supervision.

During these visits, the records of the $\mathrm{CHWs}$ are checked and problems solved, the community health nurse accompanying the $\mathrm{CHW}$ to households with specific problems. In addition she has to visit the CHWs own household ensuring this is setting a good example to the women in the community. An important aspect of the community health nurse's responsibilities toward the $\mathrm{CHWs}$ is to assist them in the planning of their work, on a weekly, monthly and annual basis.

It is difficult to see how the community health nurse can achieve anything substantial in a visit lasting a half-an-hour, leaving her little time for in-service training and following-up of cases. To name one example - a single trip from Nkhensani Hospital to Hlomela takes an hour. A return trip would mean that the community health nurse would be away from her office for at least a full morning which on the other hand shortens the time for her normal office duties.

\section{THE SURVEY}

As indicated earlier on the aim with this paper was to establish whether or not the $\mathrm{CHWs}$ has a beneficial influence on the community in which she works.

As previously explained the survey involved the administration of a questionnaire in the four villages, Hlomela, Matiyani, Riverplaats and Wayeni. The questionnaire was structured as follows: data on the family structure - question 1-7, 9-12.

history of illnesses in family - question 8 . data on nutrition - question 13-20.1. data on personal and environmental health - question 22-27.2.

An observation schedule was also developed to measure certain practical measures which $\mathrm{CHW}$ are supposed to teach to women in the community. These include the construction of toilets and refuse pits and the conservation of energy through the building of mud-stoves.

\section{Family structure}

The question was asked whether the husband lived at home or not. The response given was as follows:

$\begin{array}{lcccc}\text { Name of village } & \text { Yes } & \text { No } & \begin{array}{c}\text { No. of } \\ \text { respondents }\end{array} & \begin{array}{c}\text { \% no's of } \\ \text { total }\end{array} \\ \text { Hlomela } & 10 & 20 & 30 & 67 \\ \text { Wayeni } & 5 & 24 & 29 & 83 \\ \text { Riverplaats } & 6 & 15 & 21 & 71 \\ \text { Matiyani } & 7 & 16 & 33 & 79\end{array}$

These figures and the percentages in each case correspond with those obtained by Ijsselmuiden (1982:3), who obtained an absenteeism rate of $68 \%$ during a survey of the village of Mahatlane. Males living in these villages at the time of the survey were either locally employed (tribal or government service), on leave, on retirement, at school and in one case the husband was mentally disturbed and unfit for employment.

\section{Size of families in the four villages} HLOMELA:

Average number of children per family: 2,8 .

Number of children under 5 in the sample: 64 ( $92 \%$ of all children counted). $M A T I Y A N L$

Average number of children per family: 3,6 .

Number of children under 5 in the sample: 43 (43\% of all children counted). RIVERPLAATS.

Average number of children per family: 3,6 .

Number of children under 5 in the sample: 18 ( $24 \%$ of all children counted). WAYENI:

Average number of children per family: 3,5 .

Number of children under 5 in the sample: 26 (34\% of all children counted).

These figures are much lower than those reported in the Rand Afrikaans University Report (1983). It is impossible to explain this discrepancy as it is not clear what method the RAU Report used in their calculations.

In Hlomela 4 out of 30 families were polygamous; in Matiyani 6 out of 33; in Riverplaats 5 out of 21 ; and in Wayeni 5 out of 29 .

\section{Action taken when members of family are \\ ill}

The reason for this question was to establish from respondents the number of children who became ill during the immediate period of two months preceding the survey, what action was taken in case of illness, what kinds of illnesses were mostly prevalent and whether the assistance of the CHW was sought before remedial action was taken and what kind of action was taken.

\section{a. HLOMELA}

Ten children of respondents were currently ill in the village, 17 not and in three cases the question was not answered. In nine out of ten cases the mother sought assistance, and one treated the child herself. There was one case of pneumonia, five of influenza; two of diarrhoea; and one with an eye problem. Of these nine children, five were taken to the hospital, and four to the clinic - presumably the mobile clinic. In three cases people asked the $\mathrm{CHW}$ 's advice before taking action, five made their own decision and one was a member of the local care group (it is possible that she discussed the problems either with the $\mathrm{CHW}$ or with other members of the care group).

\section{b. MATIYANI}

In nine cases children were ill and in 24 not. None of the respondents treated the children themselves - two were taken to hospital, five to the clinic, one woman took her child to her church and in one case it is unknown what form of action was taken. There were five cases of influenza, one of diarrhoea, one sore throat and possibly also kwashiorkor and in two cases the cause of the illnesses were unknown. This village does not have a $\mathrm{CHW}$, so there was no-one to give advice before action was taken. It should also be borne in mind that this village is 15 kilometres from the nearest clinic.

\section{c. RIVERPLAATS}

Nine children of the respondents were ill in this village and twelve not. Three of the children had a cough, three diarrhoea and three had influenza. None of the respondents treated her own child - four were taken to hospital, three to the clinic (possibly the mobile unit) one to a private doctor and in one case it was not clear what steps were taken to treat the child.

\section{d. WAYENI}

Only six children of the respondents wer ill during the period under discussion, an 23 not. Two suffered from diarrhoea, one from gastro-enteritis, one of influenza, and one had an eye problem and one a back problem. None of the respondents treated their own children, in three cases the child was taken to hospital, in two to the clinic and in one to a private doctor, in four cases the children were treated by a relative, in one by a member of the local care group and in one by the nursing sister at the nearest hospital.

To summarize - it is clear that most of the complaints could be considered to be relatively minor and therefore not in need of specialized medical care. The possible exceptions to this were the one case of pneumonia, the eye problems and the child who had a back complaint.

Of the complaints listed above, $\mathrm{CHWs}$ were only trained to treat diarrhoea. Their lack of adequate curative skills has led to all the problems of loss of credibility and 'primitive' services ...' (Hammond \& Buch 1984:12).

With the exception therefore of the cases of diarrhoea listed which could normally 
be treated in the early stages with an oral rehydration solution the $\mathrm{CHW}$ is not equipped to handle any minor illnesses or emergencies. The first-aid kit issued to her is woefully inadequate. In the Mhala region people went to the extent of offering the $\mathrm{CHW}$ the normal clinic fee $(\mathrm{R} 2,00)$ for treatment to save them the expense of travelling to the nearest hospital or clinic (Hammond \& Buch 1984:12). No incidents of the same nature were found during my research.

It should also be kept in mind that most of the CHWs live in remote villages, with little or no communication with the nearest hospital or clinic. In cases of real emergency patients have to be transported at risk to the local hospital and it is doubtful whether the CHW would be able to give first aid-treatment in the case of trauma. With the meagre stocks issued to her she would hardly be able to apply firstaid when necessary.

The frequent reference by respondents to the "clinic" in the case of Riverplaats and

Wayeni may be misleading. During the Nerviews it was observed that some respondents when using the word "clinic" were actually referring in some cases to the office of the $\mathrm{CHW}$ or to the mobile clinic. It was difficult to establish to which of these respondents were actually referring. Reference to "clinic" in the answers tabled should be viewed against this fact.

\section{Breast-feeding}

A large section of the questionnaire was devoted to the gathering of information on nutrition. This information will be used elsewhere but one aspect will be highlighted in this paper, namely breastfeeding. This aspect was singled out because of the importance of breastfeeding in combating malnutrition in infants in the Third World.

The following information was obtained:

\begin{tabular}{lcccc}
\multicolumn{5}{c}{ BREAST-FEEDING } \\
& Yes & No reply & N & \% Positive \\
Hlomela & 28 & 2 & 30 & 93 \\
Matiyani & 33 & - & 33 & 100 \\
Riverplaats & 18 & 3 & 21 & 86 \\
Wayeni & 29 & - & 29 & 100
\end{tabular}

From the above results it is clear that breast-feeding does not constitute any problem in those villages.

Subsequently respondents were asked who gave them the advice to breast-feed and from their answers the following picture emerged:

$\begin{array}{lrccccccc}\text { Village } & \text { a } & \text { b } & \text { c } & \text { d } & \text { C } & \text { f } & \text { g } & \text { N } \\ \text { Hlomela } & 3 & 1 & - & 2 & 6 & 13 & 5 & 30 \\ \text { Matiyani } & 15 & - & - & - & - & 15 & 3 & 33 \\ \text { Riverplaats } & 3 & 2 & - & - & 1 & 12 & 3 & 21 \\ \text { Wayeni } & 5 & 5 & 4 & 2 & - & 13 & - & 29\end{array}$

It is interesting to note that so few of the respondents actually said that they were advised on breast-feeding by the CHW (d); or a member of the local care group (e). The usual reply was "it is our custom", or "we know that we must breast-feed our babies", hence the large number under ( $f$ ). A few respondents gave no reply to this question (g).
Action taken when a child had a "loose stomach"

$\begin{array}{lccrccc}\text { Village } & \text { a } & \text { b } & \text { c } & \text { d } & \text { No reply } & \text { N } \\ \text { Hlomela } & - & - & 4 & 22 & 4 & 30 \\ \text { Matiyani } & 1 & 1 & 13 & 16 & 2 & 33 \\ \text { Riverplaats } & - & 4 & 7 & 10 & - & 21 \\ \text { Wayeni } & - & 2 & 18 & 9 & - & 29\end{array}$

The use of the oral rehydration solution (ORS) has been strongly advocated in rural areas to combat diarrhoea and the large number of positive answers is indicative of the success of this campaign.

The logical question to ask then was where did they learn to prepare the ORS? The following replies were given in answer to this question.

$\begin{array}{lcccccccc}\text { Village } & \text { a } & \text { b } & \text { c } & \text { d } & \text { e } & \text { f } & \text { g } & \text { N } \\ \text { Hlomela } & - & - & - & 4 & 16 & - & 10 & 30 \\ \text { Matiyani } & 1 & 16 & - & - & - & 11 & 6 & 33 \\ \text { Riverplaats } & - & 5 & - & - & 1 & 1 & 14 & 21 \\ \text { Wayeni } & - & 1 & - & 1 & 2 & 1 & 24 & 29\end{array}$

$\mathrm{a}=$ your mother

$\mathrm{b}=$ Sister at clinic

$c=$ Sister at hospital

$\mathrm{d}=$ community health worker

$\mathrm{e}=$ member of local care group

$\mathrm{f}=$ other

$\mathrm{g}=$ no reply

In Hlomela and Riverplaats the majority of respondents gave their children ORS in the case of diarrhoea. The fairly large number (18) in the case of Wayeni who said that they took their children to the clinic could be ascribed to a

misunderstanding of the word "clinic". It is most likely that they actually refer to the office of the CHW - as explained earlier on - and not to the nearest clinic at Gavaza. Although there is no $\mathrm{CHW}$ at Matiyani, the large number of people who knew how to use ORS (16) could be ascribed to the influence of the sisters at the clinic at Mhinga. Those who responded that they knew how to use ORS in the case of diarrhoea knew also in the majority of cases how actually to prepare the solution - a fact hammered home by the clinic's sisters throughout Gazankulu. What is interesting however, is that so few people (Hlomela 4 and Wayeni 1) actually said that they received this information from the $\mathrm{CHW}$.

\section{Responsibility for administering medicine in case of illness}

The aim of this question was to establish whether the $\mathrm{CHW}$ was consulted in case of illness, bearing in mind that one of her duties was surveillance of possible illnesses in the community. In both Riverplaats and Wayeni all the respondents said that they alone were responsible for administering medicine to their children. In Matiyani a large number of respondents said it was the sister at the clinic at Mhinga who administered medicine to their children and in Hlomela the majority did not respond to this question. However, it is doubtful whether the respondents actually understood this question even though it was explained over and over again and hence no valid conclusions could be derived from their answers.
Asked what action they themselves took in the case of illness the majority replied that they either went to the nearest clinic or hospital

\section{Environmental hygiene}

In the following group of questions the existence and use of pit latrines were tested together with questions on the presence of flies as important vectors of communicable diseases.

Asked whether the household possessed a pit latrine or not, the following results were obtained:

$\begin{array}{lccccc}\text { Village } & \text { Yes } & \% & \text { No } & \% & \text { N } \\ \text { Hlomela } & 23 & 76,7 & 7 & 23,3 & 30 \\ \text { Matiyani } & 24 & 42,7 & 9 & 27,6 & 33 \\ \text { Riverplaats } & 15 & 71,4 & 6 & 28,6 & 21 \\ \text { Wayeni } & 23 & 79,3 & 6 & 20,7 & 29\end{array}$

In the observation schedule (which results will be discussed further on) the actual existence and condition of pit latrines were checked by the author or his assistant. The following results were obtained:

$\begin{array}{lcrrrcc}\text { Village } & \text { Yes } & \% & \text { No } & \% & \text { No reply } & \text { N } \\ \text { Hlomela } & 16 & 53,5 & 11 & 36,7 & 3 & 30 \\ \text { Matiyani } & 19 & 57,6 & 10 & 30,3 & 4 & 33 \\ \text { Riverplaats } & 14 & 66,6 & 7 & 33,3 & - & 21 \\ \text { Wayeni } & 21 & 72,4 & 8 & 27,6 & - & 29\end{array}$

It is difficult to explain the difference between the answers obtained from the respondents and what was actually found. It can perhaps be attributed to the fact that the tribal authority is responsible for the enforcement of the digging of pit latrines in the villages. This fact was borne out by the replies given to the question: Who told you to build a pit latrine? table:

The replies are reflected in the following

$\begin{array}{lrrrrrrrrr}\text { Village } & \text { a } & \text { b } & \text { c } & \text { d } & \text { e } & \text { f } & \text { g } & \text { No reply } & \text { N } \\ \text { Hlomela } & 11 & - & - & - & - & 11 & - & 8 & 30 \\ \text { Matiyani } & 18 & 3 & - & - & - & - & - & 12 & 33 \\ \text { Riverplaats } & 7 & 3 & - & 1 & - & 2 & - & 8 & 21 \\ \text { Wayeni } & 9 & 3 & - & - & 1 & 10 & - & 6 & 29\end{array}$

$\mathrm{a}=$ Chief $/$ headman

$\mathrm{b}=$ Sister at clinic

$\mathrm{c}=$ Health inspector

$\mathrm{d}=$ Community health worker

$\mathrm{e}=$ Member of the local care group

$\mathrm{f}=$ Radio Tsonga

$\mathrm{g}=$ School teacher

As could be seen in the majority of cases respondents were advised (instructed?) by the local tribal authority (chief/headman) to build a toilet, namely Hlomela $(36,7 \%)$; Matiyani $(54,5 \%)$; Riverplaats $(33,3 \%)$; and Wayeni (31\%). In the case of Hlomela $(36,7 \%)$ and Wayeni $(34,5 \%)$ the women interviewed said that they were advised to build a pit latrine by a member of the local care group. One could therefore argue that in the case of Hlomela and Wayeni the community health worker did have some influence in the erection of pit latrines through the local care groups.

Flies play an important role in the transmission of diseases such as trachoma, diarrhoea, etc. and for this reason respondents were asked whether flies could be considered bad for one's health? 
The response to this question was as follows:

$\begin{array}{lcccc}\text { Village } & \begin{array}{c}\text { Yes, they } \\ \text { are bad }\end{array} & \text { No } & \text { No reply } & \text { N } \\ \text { Hlomela } & 27 & 3 & - & 30 \\ \text { Matiyani } & 24 & 9 & - & 33 \\ \text { Riverplaats } & 20 & 1 & - & 21 \\ \text { Wayeni } & 29 & - & - & 29\end{array}$

From these answers it can be seen that the majority of respondents did have some knowledge about the effect of flies on health. In the following question they were asked why they were bad and again in the majority of cases the response was that they cause diseases. Asked where did they learn this, the following information was obtained:

$\begin{array}{lrrrrrrrrrr}\text { Village } & \text { a } & \text { b } & \text { c } & \text { d } & \text { e } & \text { f } & \text { g } & \text { h } & \text { No reply } & \text { N } \\ \text { Hlomela } & 2 & - & - & - & - & 16 & 2 & 7 & 3 & 30 \\ \text { Matiyani } & 6 & - & 1 & - & 7 & - & - & 18 & 1 & 33 \\ \text { Riverplaats } & - & - & - & - & - & 2 & - & 6 & 13 & 21 \\ \text { Wayeni } & 5 & 2 & 1 & - & - & 10 & 2 & 4 & 5 & 29\end{array}$

$\mathrm{a}=$ Clinic

b $=$ Hospital

$c=$ Radio Tsonga

$\mathrm{d}=$ Friend $/$ relative

$\mathrm{e}=$ Sister at clinic

$\mathrm{f}=$ Member of the local care group

$\mathrm{g}=$ Community health worker

$\mathrm{h}=$ Other

It is clear that in the case of Hlomela and Wayeni this knowledge was gained through the local care group. Again it can be argued that the $\mathrm{CHW}$ did have some influence through the local care group in their respective villages. The large number of respondents at Matiyani who did not give a conclusive answer (18/33) but said they learned it "somewhere" refers to knowledge/information passed in the village by word of mouth. Of the 18 three indicated that they learned it at school and one that she was advised by the local headman.

In the last question in this group respondents were asked what measures they took against contamination of their food by flies, particularly when they were handling food. The replies can be reflected as follows:

$\begin{array}{lccrc}\text { Village } & \text { a } & \text { b } & \text { c } & \text { N } \\ \text { Hlomela } & 13 & 4 & 13 & 30 \\ \text { Matiyani } & 18 & - & 15 & 33 \\ \text { Riverplaats } & 14 & - & 7 & 21 \\ \text { Waycni } & 11 & - & 18 & 29\end{array}$

$a=$ Keep food covered

$\mathrm{b}=$ Prepare food

$c=$ Nothing

In the case of Hlomela $43,3 \%$ said that they keep their food covered or did nothing - the usual response being "we just sweep the flies away with our hands" In the case of Matiyani $54,5 \%$ said that they keep their food covered, while $45,5 \%$ did nothing. In the case of Riverplaats $66,7 \%$ kept their food covered and $33,3 \%$ did nothing. In the case of Wayeni $37,9 \%$ kept their food covered, while $61,2 \%$ said that they did nothing.

The results of Wayeni - where there is a $\mathrm{CHW}$ - is interesting, especially when it is compared with that of Matiyani, where a larger percentage said that they keep their food covered than those who did nothing.
The fact that people indicated that they kept their food covered, was confirmed by observation during the interviews.

A final aspect under this heading is the existence of refuse pits. Information on this was obtained through an observation schedule. The following results were obtained:

$\begin{array}{lcccccc}\text { Village } & \text { Yes } & \% & \text { No } & \% & \text { No reply } & \text { N } \\ \text { Hlomela } & 17 & 56,7 & 11 & 36,7 & 2 & 30 \\ \text { Matiyani } & 12 & 42,4 & 19 & 57,5 & - & 33 \\ \text { Riverplaats } & 12 & 57,1 & 9 & 42,9 & - & 21 \\ \text { Wayeni } & 21 & 72,4 & 8 & 27,6 & - & 29\end{array}$

In most of the cases these refuse pits were uncovered shallow holes in the ground. Only in a few instances were attempts made to cover the holes with grass or something similar. Usually the refuse pits were just outside the homestead - sometimes at the back and sometimes on the side of the hut. The high incidence of uncovered refuse pits tended to give the villages an untidy unkempt appearance. In Hlomela the CHW did have a refuse pit large and deep - but the refuse was left uncovered.

\section{Personal hygiene}

In this group of questions respondents were asked when they have to wash their hands and where they learned this.

When asked when they have to wash their hands the following replies were given:

Village
Hlomela
Matiyani
Riverplaats
Wayeni
*In this case more than on
question.
a = Prepare food
b = Eat
c $=$ Feed a child

As could be read from the replies the majority of people knew they had to wash their laands when handling food, during its preparation and also when eating.

However, the number of children who ate or handled food with unwashed hands observed during interviews was quite high.

In the next question respondents were asked if they have to wash after relieving themselves. Their replies are reflected in the following table:

$\begin{array}{lrrrrrrrrrr}\text { Village } & \text { a } & \text { b } & \text { c } & \text { d } & \text { e } & \text { f } & \text { g } & \text { h } & \text { i } & \text { N } \\ \text { Hlomela } & - & 1 & 3 & - & - & - & 15 & 2 & 9 & 30 \\ \text { Matiyani } & 5 & 1 & 3 & - & - & 2 & - & - & 22 & 33 \\ \text { Riverplaats } & 6 & 1 & 2 & 1 & - & - & 3 & 1 & 7 & 21 \\ \text { Wayeni } & 4 & 2 & 3 & 1 & 1 & - & 9 & 4 & 7 & 29\end{array}$

-More than one answer was given to this question.

$\mathrm{a}=$ Clinic

$\mathrm{b}=$ Hospital

$\mathrm{c}=$ School

$\mathrm{d}=$ Radio Tsonga

$\mathrm{e}=$ Friend $/$ Relative

$\mathrm{f}=$ Sister at clinic

$\mathrm{g}=$ Member of the local care group

$\mathrm{h}=$ Community health worker

$\mathrm{i}=$ Other

Here again it could be argued that the large number of persons who said that they received this information through the local care groups (Hlomela - 16, Wayeni - 9) was due to the work done by the CHW. The large number of people at Matiyani (22) who could not give any reply to this question could be indicative of the remoteness of this village and possibly also because there is neither a care group nor a $\mathrm{CHW}$ working in the village.

\section{Knowledge of one particular disease}

In this group of questions the knowledge of respondents about one particular disease was tested. Malaria was chosen because Gazankulu falls within the "malaria belt" of the Transvaal and there is a high incidence of the disease particularly during the rainy season. The responses to these questions were as follows:

The first question was what disease is caused by mosquitoes. The following replies were received:

$\begin{array}{lcc}\text { Village } & \text { Know } & \text { Doesn't know } \\ \text { Hlomela } & 2 & 28 \\ \text { Matiyani } & 2 & 31 \\ \text { Riverplaats } & 1 & 20 \\ \text { Wayeni } & 2 & 27\end{array}$

30
33
21
29

The few who knew the answer to this question had learned the information from the hospital (2); the clinic (2); school (2); member of the care group and in the one case the $\mathrm{CHW}$ was the respondent and knew the correct answer.

The last question was that if there were mosquitoes in and around the homestead what did they do about it? The replies given can be reflected as follows:

$\begin{array}{lcccccc}\text { Village } & \text { a } & \text { b } & \text { c } & \text { d } & \text { No reply } & \text { N } \\ \text { Hlomela } & 10 & 19 & - & - & 1 & 30 \\ \text { Matiyani } & 16 & 15 & 2 & - & - & 33 \\ \text { Riverplaats } & 14 & 7 & - & - & - & 21 \\ \text { Wayeni } & 21 & 8 & - & - & - & 29\end{array}$

$\mathrm{a}=$ nothing

$\mathrm{b}=$ kill them

$\mathrm{c}=$ smoke them out

$\mathrm{d}=$ huts are sprayed by the malaria team

The large number of respondents who did nothing about mosquitoes are quite significant Hlomela (33,3\%); Matiyani $(48,5 \%)$; Riverplaats $(67,7 \%)$; Wayeni $(72,4 \%)$ bearing in mind the high incidence of the disease in that areas. The usual method of combating the pest is by spraying an insecticide, but although many respondents said that they use Doom, when asked they did not have any in the house. It is regular practice that all the huts are sprayed by malaria teams which made lack of knowledge about the disease even more remarkable considering also the replies given to $d$ above.

\section{Fuel-saving devices}

CHWs are taught during training to encourage the use of fuel-saving devices such as the construction of mud-stoves or the use of wonderboxes, as a means of conserving energy. Use of mud-stoves can also be an aid in preventing serious burns, particularly during the winter, when young 
toddlers often fall into open fires in the cooking huts.

The existence of mud-stoves was therefore included in the observation schedule. The following results were obtained:

$\begin{array}{lcccc}\text { Village } & \text { Yes } & \text { No } & \text { No reply } & \text { N } \\ \text { Hlomela } & 8 & 20 & 2 & 30 \\ \text { Matiyani } & - & 33 & - & 33 \\ \text { Riverplaats } & 4 & 17 & - & 21 \\ \text { Wayeni } & - & 29 & - & 29\end{array}$

Of these the results of Wayeni, where there is a $\mathrm{CHW}$, is quite remarkable. It should be borne in mind that building a mud-stove is no easy task but still the relative absence of mud-stoves in the three villages where a $\mathrm{CHW}$ is working is rather difficult to explain.

\section{CONCLUSION}

Earlier in this paper it was stated that the aim of this study was to establish whether the CHW has a positive influence on the

th status of the local community where she has been posted.

It is expected of the CHWs that they encourage the construction of pit latrines. But it is also one of the duties of the tribal authorities to ensure a basic standard of environmental hygiene in the villages. It is therefore difficult to establish how many pit latrines were built in a particular village since the CHW started to work there. In Hlomela $(76,7 \%)$ of respondents did have a pit latrine, Riverplaats $(71,4 \%)$ and Wayeni $(79,3 \%)$, but in Matiyani where no CHW is working $(72,7 \%)$ of the respondents had pit latrines. It is therefore very difficult to state unequivocally that the $\mathrm{CHWs}$ were responsible for the high incidence of pit latrines in Hlomela,

Riverplaats and Wayeni.

The same argument could be used in the case of immunizations. Observation showed that in Hlomela the total number of-immunizations increased after the fe was included in the itinerary of the mobile unit, but it is very difficult to give the exact percentage of this increase.

There is also another factor to be taken into account when evaluating the work of CHWs. The use of CHWs is a relatively recent phenomenon in South Africa. Community or village health workers are employed in some of the so-called national states or TBVC countries, but in most cases purely on an ad hoc basis. It was often a case of the local medical superintendent taking the initiative in the training and employment of CHWs, as in KwaZulu at the Benedictine, Bethesda, Charles Johnson and Manguzi Hospitals.

Gazankulu, on the other hand, is the only "national state" where the CHW actually forms an integral part of the health service delivery system. This practice is also fairly recent - the first group was only trained in 1980, and, as has already been indicated, the training programme has been reconsidered. Karlsson (1978:728) is of the opinion that the $\mathrm{CHWs}$ deliver a measure of primary health care to remote rural areas. Not all of them were successful, and some of them did in fact have a negative influence on the communities where they were placed (Karlsson, 1983:728; Hammond \& Buch 1984). A few observations can, however, be made.

On the level of personal hygiene it could be argued that the CHWs had a positive influence. People knew when to wash their hands, that flies carry germs and that one should keep food covered. No significant differences could be observed between Hlomela, Wayeni and Riverplaats on the one hand, and Matiyani on the other.

Without exception streets in the four villages were unkempt and untidy, with large puddles of water around the standpipes - ideal breeding places of mosquitoes. This accords with the conclusion of Hammond \& Buch (1984:16) with regard to Mhala.

In Hlomela, Wayeni, and Riverplaats few people knew what the community health worker is. She was more often known as the "nurse". This was reinforced by the blue uniform she was wearing - the same as that of the hospital staff. In one of the villages it was remarkable that even people living in close proximity of the CHW could not point out the homestead of the CHW or did not know what her name is. Hammond \& Buch (1984:7) went so far as to say that the fact that she wears a uniform brought distance between her and the community.

The question "what causes malaria?" was deliberately chosen to test the knowledge of the local population about at least one disease. Malaria is endemic in Gazankulu and it was indeed remarkable how few people in the four villages knew that the disease is caused by mosquitoes. Nevertheless homesteads are regularly sprayed by the malaria teams.

It is expected of the CHWs to visit each household at least once a year. It is extremely doubtful whether this aim is ever fulfilled. In many of the households in one village where interviews were conducted the people present did not know the $\mathrm{CHW}$ although she had been working in that particular village for more than three years.

The health support system of the CHW could be improved. The $\mathrm{CHW}$ is only visited once a month by the community health nurse and often less than this. The fact that the monthly mileage travelled by these nurses has been curtailed also has an influence. A possible solution would be to appoint a separate supervisor for the CHWs.

Communication of the CHW with the nearest clinic, health centre or hospital is very poor. In three of the villages no radio or telephone communication existed between the village and the nearest health facility. In addition the kit issued to her is insufficient to handle routine complaints let alone an emergency. Shops in the villages had a better supply of patent medicines than the CHW (Hammond \& Buch 1984:12). This left the people with the impression that the local shopkeeper is better equipped than the CHW to handle routine complaints.

One could but agree with the conclusion of Hammond \& Buch $(1984: 10)$ that “... of all rural health workers, a lone village based worker is potentially the most geographically, socially and intellectually isolated." It has been shown that this was often done deliberately, but something will have to be done to improve this state of affairs. Without sufficient support from the community health nurse and other medical staff it is difficult to see how CHWs can deliver a proper primary health care service.

In the Nkhensani health ward the community health nurse brought the CHWs together for a refresher course. This also happened in other health wards (Karlsson 1983:728), but this practice should be extended to all the health wards and organised on a regular basis.

Another matter which deserves urgent attention is the issuing of medication by the $\mathrm{CHW}$. This matter is under investigation by the SA Nursing Council but this body is not in the position to relax the conditions under which CHWs should issue medicine. However, the question could be asked whether it is sensible to apply First World standards to Third World conditions without the suitability of these standards being examined?

All in all I would like to agree with Karlsson (1983:728) that there is indeed a place for the $\mathrm{CHW}$ in the health service delivery system. Many of the remote rural villages cannot easily be reached by the health service delivery system. In these communities the $\mathrm{CHW}$ can contribute to the raising of the health status of the local communities especially in personal and environmental hygiene. If the $\mathrm{CHW}$ is appropriately trained she could make a valuable contribution in the early detection of diseases, and pregnancies, support and care of the aged and the chronically ill

The sense of isolation in which the $\mathrm{CHW}$ works should be addressed in some or other way because this is a major contributing cause of frustration and a general lowering of the already poor standards of the health care service she is supposed to give.

\section{ENDNOTES}

1. The author acknowledges the contribution of officials of the Division Nutrition of the Department of National Health and Population Development in the formulation of questions on nutrition. Copies of the questionnaire are available from the author on request.

2. The care groups give a direct input to community health in Gazankulu (cf. Karlsson, 1983 and Sutter, 1979, 1983).

3. The main conclusion of the research by Hammond \& Buch (1984), is that the CHWs do not meet the expectations which their introduction as an important auxiliary in community health in Gazankulu raised. Karlsson (1983) merely gave an overview of the establishment and functioning of the care groups with little attempt at evaluating their work. It was hoped that this piece of research will supplement 
the scant information on the $\mathrm{CHWs}$ as an important facet in the health service delivery system of Gazankulu.

4. During the research, the author established that Hlomela was included in the itinerary of the mobile unit after a request of the $\mathrm{CHW}$.

5. "House" or "household" means the number of huts occupied by one family irrespective of whether it is monogamous or polygamous family. This implies that a household - judged in terms of its size - would consist of four huts (the normal pattern is four). In the case of poor families or newlyweds, there is only one hut. "Hut" instead of "house" is used because the latter has a specific Western connotation.

6. A random sample numbering table was used to draw the sample.

7. Karlsson was Secretary of Health and Welfare during the time the first group of $\mathrm{CHWs}$ was trained.

\section{BIBLIOGRAPHY}

De Kadt, E., Segall, M. 1981. Health needs and health services in rural Ghana. Social Science and Medicine, vol. I5A, no. 4.

Gazankulu, Department of Health and Welfare. Blueprint of Objectives $1978-83$.

Gazankulu, Department of Health and Welfare. Budget speech.

Hammond, M., Buch, E. 1984. Community health workers in Mhala, Gazankulu: Perversion of a progressive concept? Second Carnegie Inquiry into poverty and development. Cape Town.

ljsselmuiden, C.G. 1981. Report from a survey held in Mahatlane, 29/3-1/4/1982. Unpublished report Elim-hospital

ljsselmuiden, C.G. (n.d.) Nutritional status and blood pressures of adults in Northern Gazankulu. Elim-hospital.

Kok, P.W., Kwamanga, D. 1982. A simple random survey method for the expanded programme on immunization. Current medical research in Eastern Africa, in Tukei, P.M., Kjogu, A.R. (eds.) Proceedings of the Third Annual Medical and Scientific Conference, Nairobi.

Karlsson, E.L. 1983. Community health workers in rural areas: experiences in training and utilization. Israel Journal of Medical Sciences, vol. 19 , no. 8.
Rand Afrikaans University. 1983. $A$ development framework for Gazankulu, vols. 1 and 2. Johannesburg: Rand Afrikaans University, Institute for Development Studies.

Sutter, E.E. n.d. personal papers, Elim-hospital.

Werner, D. 1981. The village health worker lackey or liberator? World Health Forum, vol. 2 , no. 1

Werner, D. 1980 . The village health care programme: Community-supportive or community-oppressive? Contact. 57.

World Health Organization. 1978. International Conference on Primary Health Care. Primary health care. Geneva: World Health Organization.

World Health Organization. 1981. Global strategy for health for all by the year 2000 Geneva: World Health Organization.

World Bank. 1977. Basic needs: A progress report. Policy planning and program Review Department (mimeo). Washington, D.C.: World Bank.

J.C.N. Mentz, D.Litt et Phil. (UNISA) Senior Lecturer

Department of Development Administration and Politics

\section{Subscription rates/Subskripsie-tariewe}

Curationis is published bi-annually.

Curationis word twee keer per jaar uitgegee.

Send your name and address plus cheque/postal order

for R31,96 (R25 + GST R3,00 + delivery charges R3,96) to:

Stuur $u$ naam en adres plus tjek/posorder vir R31,96

(R25 + AVB R3,00 + afleweringskoste R3,96) aan:

Juta Subscription Services

Free Post CT 151

Kenwyn 7790

Cape Town

South Africa 